(c) American Dairy Science Association, 2006.

\title{
Body Condition Assessment Using Digital Images
}

\author{
J. D. Ferguson, ${ }^{\star 1}$ G. Azzaro, $†$ and G. Licitra†‡ \\ *University of Pennsylvania, School of Veterinary Medicine, Kennett Square 19348 \\ †Consorzio Ricerca Filiera Lattiero Casearia (CoRFiLaC), Ragusa, Italy \\ ¥University of Catania, Catania, Italy
}

\begin{abstract}
This project assessed the ability to assign a body condition score (BCS) to a dairy cow from digital photographs or videos. Images were taken from the rear of the cow at a 0 to $20^{\circ}$ angle relative to the tail head. Four observers assigned a BCS to each of 57 cows at a farm visit (live, farm 1) and later from a photograph (photo). Means \pm standard deviations of BCS by method and observer were as follows: live $=3.25 \pm$ $0.51,3.42 \pm 0.49,3.32 \pm 0.58,3.13 \pm 0.62$; photo $=3.36$ $\pm 0.52,3.32 \pm 0.43,3.44 \pm 0.62,3.14 \pm 0.6$ for observers 1 to 4 , respectively. Body condition score means differed across observers for live (observer 2 higher and observer 4 lower, compared with observers 1 and 3) and photo methods (observer 3 lower, compared with observers 1, 2, and 3); however, within observer, the mean live BCS did not differ from the mean photo BCS. Correlation coefficients between BCS assigned live and from photos were $0.84,0.82,0.82$, and 0.90 for observers 1 to 4, respectively. Subsequently, observer 1 visited 2 farms, assigned a live BCS, and digitally photographed 187 cows (56 and 131 cows from farms 2 and 3 , respectively). Observers 2,3 , and 4 assigned a BCS from the photographs. Means \pm standard deviations of BCS by observer (method) were 1 (live) $3.35 \pm 0.55 ; 2$ (photo) $3.33 \pm 0.49 ; 3$ (photo) $3.60 \pm 0.54$; and 4 (photo) $3.26 \pm 0.62$. The mean BCS for observer 3 was higher and that for observer 4 was lower than for observers 1 and 2. Correlation coefficients between observer 1 and observers 2 through 4 were $0.78,0.76$, and 0.79 , respectively. Observer 1 assigned a BCS to 41 cows at a farm visit and $3 \mathrm{wk}$ later assessed the BCS of cows from a video taken at a farm visit by a different individual. Cows were restrained in headlocks at a feed bunk when assessing BCS and for video production. No difference was detected for the mean BCS, for the standard deviation of the mean BCS, or in the distribution of BCS between the live and video assessments. Mean
\end{abstract}

Received February 25, 2006.

Accepted May 2, 2006.

${ }^{1}$ Corresponding author: ferguson@vet.upenn.edu and SD for 17 groups of Holstein cows from 20 farms were used to generate 10,000 random samples of BCS. Groups of 25, 50, 100, and 150 cows were created from the random samples, and estimates of mean BCS were determined by sampling 3 to $80 \%$ of the group. Estimates of mean BCS with a sample size of $30 \%$ or more from a group of cows fell within the $95 \%$ confidence limit of the true mean more than $98 \%$ of the time. Digital photographs provide adequate imaging for assessment of BCS. Sampling 30\% of a group should be adequate to assess the mean BCS. Video imaging allowed a rapid assessment of BCS but did not permit identification of individual cows.

Key words: body condition score, dairy cattle, digital imaging

\section{INTRODUCTION}

Assessment of body condition in dairy cattle is a simple, repeatable system to evaluate body fat stores and estimate cumulative energy balance (Otto et al., 1991; Ferguson et al., 1994; Komaragiri and Erdman, 1997). The score range used by most dairy management advisors applies a scale from 1 to 5 , with 1 representing emaciated cows and 5 representing obese cows (Wildman et al., 1982). Edmonson et al. (1989) developed a descriptive chart to aid in assessing BCS, whereas Ferguson et al. (1994) devised a system based on statistical associations of descriptions of body regions. It is possible to separate BCS into 0.25-point increments between scores of 2 to 4 ; however, this degree of resolution may not be possible with BCS of $<2$ and $>4$ (Ferguson et al., 1994). It is generally recommended that cows with a BCS of $>3.5$ are too fat and that cows having a BCS of $<2.5$ are too thin (Domecq et al., 1997a,b). Extremes in BCS and BCS loss are associated with health risks and reduced reproductive efficiency (Gearhart et al., 1990; Ruegg and Milton, 1995; Domecq et al., 1997a,b).

Advisors to dairy herds may be local, providing services to dairy farm managers on a routine schedule. Local farm contacts usually include veterinarians, field staff from nutritional companies, or county extension agents. At times, local advisors seek advice from 


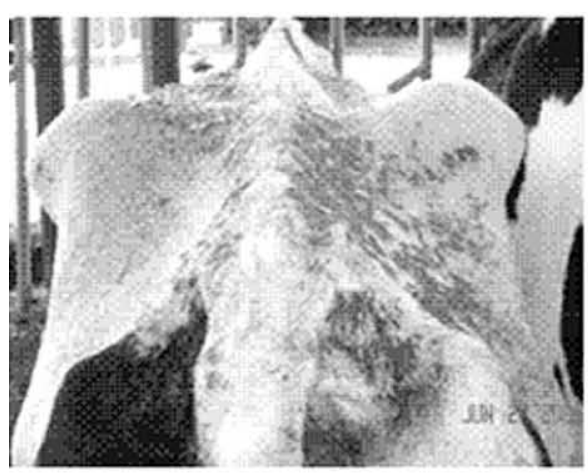

$\mathrm{BCS}=1$

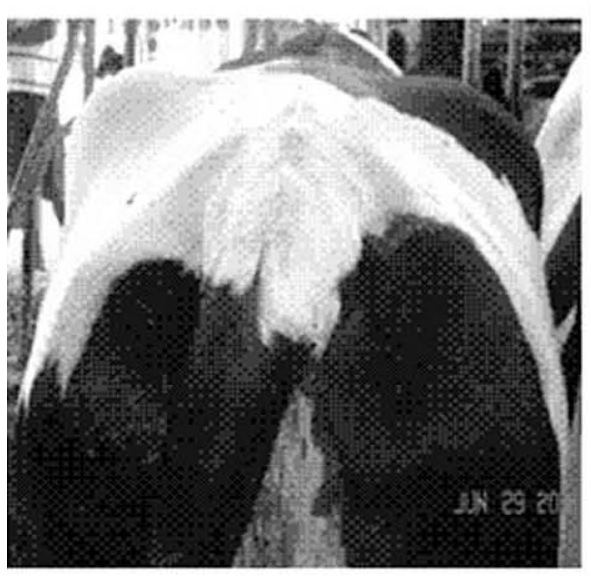

$\mathrm{BCS}=4$
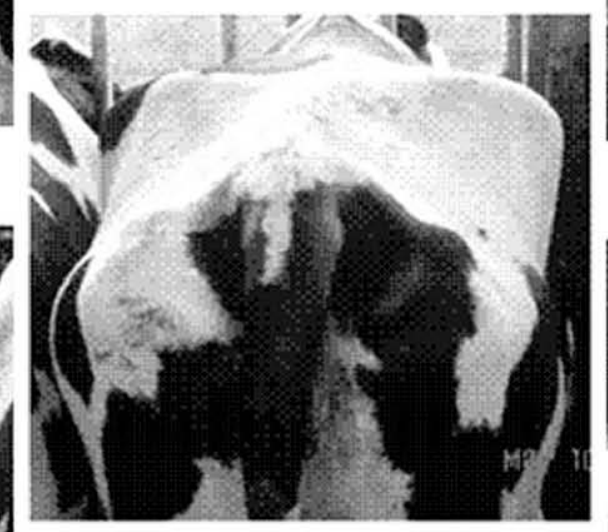

$\mathrm{BCS}=3$

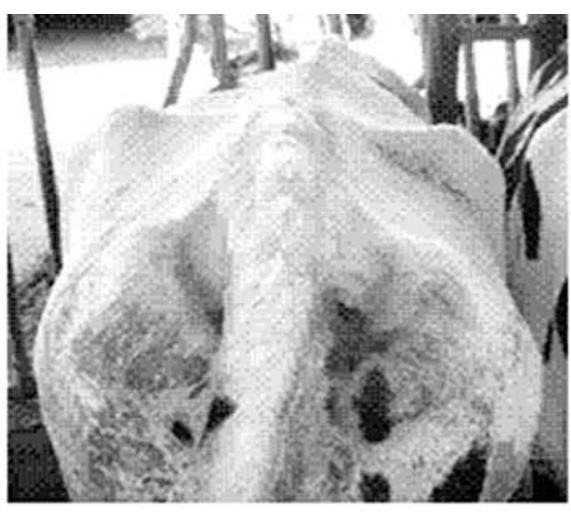

$\mathrm{BCS}=2$

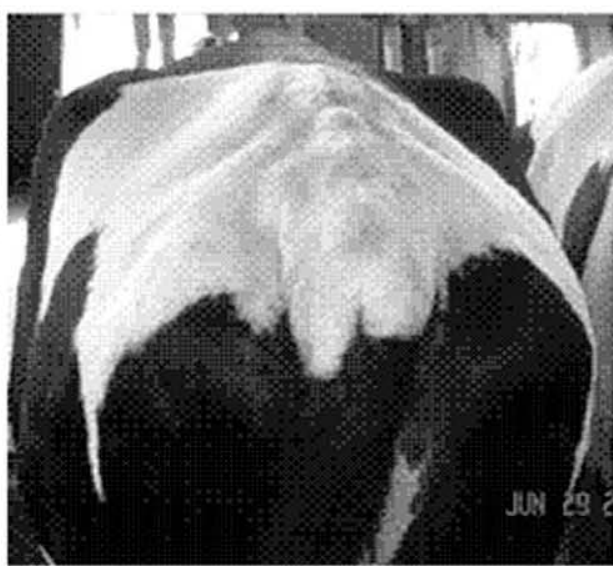

$\mathrm{BCS}=5$

Figure 1. Images of cows assigned a body condition score of $1,2,3,4$, or 5 .

a distant, secondary "expert" for a specific problem. Secondary advisors may be independent consultants, university faculty, or technical support staff working within the same company as local advisors. Bringing an outside advisor to the farm can be costly because experts often are not located in proximity to farms. Expert staff within a company can be overscheduled, finding it difficult to visit farms to support local advisors. In addition, herd problems may occur simultaneously at different locations that require attention, and it may not be possible to visit the farms in a timely fashion.

When consulting on production, reproduction, and health problems in dairy herds, nutritional advisors typically want information on BCS. Primary advisors can assess BCS directly from routine farm visits. Consultants may be able to obtain information on BCS from DHI records or other farm databases, but many herds do not routinely collect BCS observations. Verbal descriptions of BCS can be communicated from field staff to the advisor, but often secondary advisors desire to make their own visual assessment.

Digital photos and videos are easily accessible and transportable. Images can be easily shared through email and Web sites. Secondary advisors can view these images and make assessments of farm facilities and the BCS of cows. Pictures and videos may be captured at the time of the problem, and additional images captured at an earlier time period may be provided. Providing access to digital images along with data on production, reproduction, and health may enable secondary advisors to support local advisors without physically visiting the farm, thus reducing costs. Stored video files over a 4-d period have been used to assess cow behavior (Overton et al., 2002). The purpose of this project was to assess the utility of using digital or video images to evaluate the BCS of a group of cows. Our second aim was to construct a model to determine the sample size needed to estimate the mean BCS of a group of dairy cows. 
Table 1. Mean and distribution of BCS by observer for 57 cows assigned a BCS by visual observation on the farm vs. a BCS assigned based on a digital posterior photograph ${ }^{1}$

\begin{tabular}{|c|c|c|c|c|c|c|}
\hline \multirow[b]{2}{*}{ Observer } & \multicolumn{6}{|c|}{ Mean BCS } \\
\hline & Live & SE & Photo & SE & Difference & SE \\
\hline Observer 1 & $3.25^{\mathrm{b}}$ & 0.07 & $3.36^{\mathrm{a}}$ & 0.07 & $-0.11^{b}$ & 0.04 \\
\hline Observer 2 & $3.42^{\mathrm{a}}$ & 0.07 & $3.32^{\mathrm{a}}$ & 0.07 & $0.10^{\mathrm{a}}$ & 0.04 \\
\hline Observer 3 & $3.32^{\mathrm{ab}}$ & 0.07 & $3.44^{\mathrm{a}}$ & 0.07 & $-0.12^{\mathrm{b}}$ & 0.04 \\
\hline \multirow[t]{2}{*}{ Observer 4} & $3.13^{\mathrm{c}}$ & 0.07 & $3.14^{\mathrm{b}}$ & 0.07 & $-0.01^{\mathrm{b}}$ & 0.04 \\
\hline & \multicolumn{3}{|c|}{ Correlation (photo vs. live) } & & & \\
\hline All observers & & 0.84 & & & & \\
\hline Observer 1 & & 0.84 & & & & \\
\hline Observer 2 & & 0.82 & & & & \\
\hline Observer 3 & & 0.82 & & & & \\
\hline Observer 4 & & $0.90 *$ & & & & \\
\hline
\end{tabular}

\footnotetext{
${ }^{\mathrm{a}, \mathrm{b}}$ Means within column having different superscript letters differ $(P<0.05)$.

${ }^{1}$ Live $=$ BCS assigned by visual and tactile observation of cows restrained in headlocks, standing in free stalls, or in open lots; photo = BCS assigned by examining a digital photo made from behind the cow at a 0 to $20^{\circ}$ angle to the tail head, parallel to the spinal axis; difference $=$ mean difference in BCS (live minus photo for each cow by observer).$$
* * * P<0.001 \text {. }
$$

\section{MATERIALS AND METHODS}

\section{BCS and Digital Imaging}

Holstein cattle BCS and digital images were collected from 3 farms (farm 1, 62 cows; farm 2, 140 cows; and farm 3, 60 cows). Cows were housed in free stalls, a bedded pack, or an open lot depending on the production and the farm. Pictures of cows were made either as they were restrained in headlocks at feed mangers, as they were standing in free stalls, or as they were standing in bedded pack or lot areas. Digital photographs were made by 1 individual, who also assigned a BCS to each cow (observer 1). Multiple images were recorded for each cow, which included lateral, anterior, and posterior views. Anterior and posterior views were made at varying angles and elevations relative to the spinal axis of the cow. Images were copied to a central server and coded for viewing, obscuring farm and cow identification. Photographs were organized into different files based on the photographic orientation. Three nutritional advisors (observers 2 through 4) from Consorzio Ricerca Filiera Lattiero Casearia (CoRFiLaC, Ragusa, Italy) were asked to independently assess BCS from the images.

All 4 observers visited farm 1 to evaluate BCS. Several days later, each observer independently recorded a BCS from the digital image collected during the farm visit. Two farms were visited by observer 1 , who assigned a BCS to cows and photographed each cow (140 and 60 cows, farms 2 and 3, respectively). Observers 2,3 , and 4 were asked to assess the BCS only from the photographs taken at each farm.
Data was structured by herd, cow, and observer. A total of 262 cows were photographed from the 3 farms. Each cow image was classified based on location [lockup (191 cows), standing in free stalls (9 cows), or loose in the bedded pack, alley, or open lot (62 cows)], and view (lateral, anterior, posterior, and angle). In addition, cows were classified based on color, ranging from all white (W, 37 cows) to all black (B, 45 cows), with varying intermediate markings. Intermediate markings were judged based on the proportion of black and white markings as follows: black-black-white (BBW, 90 to $65 \%$ black relative to white, 25 cows); black-white (BW, 51 to $60 \%$ black, 53 cows); whiteblack (WB, 51 to $60 \%$ white relative to black, 61 cows); and white-white-black (WWB, 90 to $65 \%$ white relative to black, 36 cows). Five cows did not have a color scheme assigned.

One farm (farm 2) was revisited 1 mo later to make a video recording of cows (41 animals) locked in head restraints at the feed manger. The BCS of each cow was assessed at that time by observer 1 from cows locked in head restraints. Two weeks later, the BCS was assessed from this video by observer 1 . The distribution of BCS from the video assessment was compared with that from the farm visit.

\section{Simulation Model}

Means and standard deviations of BCS for 17 lactating and nonlactating Holstein cow groups were used to generate random samples of BCS data using @Risk software (Palisade Corp., Newfield, NJ). Groups of cows were compiled from 20 dairy farms. The physical 
Table 2. Distribution of differences by observer for BCS assessed from cows on the farm (live) and from photographs (photo) ${ }^{1}$

\begin{tabular}{lcccc}
\hline & \multicolumn{4}{c}{ Observer } \\
\cline { 2 - 5 } Difference & 1 & 2 & 3 & 4 \\
\hline-1.0 & 2 & 0 & 0 & 0 \\
-0.75 & 1 & 0 & 5 & 1 \\
-0.50 & 4 & 2 & 6 & 4 \\
-0.25 & 17 & 7 & 20 & 13 \\
0 & 25 & 27 & 13 & 23 \\
0.25 & 7 & 12 & 8 & 12 \\
0.50 & 0 & 7 & 4 & 3 \\
0.75 & 1 & 1 & 0 & 1 \\
1.0 & 0 & 1 & 1 & 0 \\
Percent \pm 0 to 0.25 & 86.0 & 80.7 & 71.9 & 84.2 \\
Total & 57 & 57 & 57 & 57 \\
\hline
\end{tabular}

${ }^{1}$ Live $=$ BCS assigned by visual and tactile observation of cows restrained in headlocks, standing in free stalls, or in open lots; photo = BCS assigned by examining a digital photo made from behind the cow at a 0 to $20^{\circ}$ angle to the tail head, parallel to the spinal axis; difference $=$ BCS live minus BCS photo. Range for live $=2.0$ to 4.75 ; range for photo $=2.0$ to 4.50 .

organization of cows within the dairy herd constituted a group. The group was described as an input for the simulation model based on the mean BCS and standard deviation for the group of cows. When groups in different herds had the same mean BCS and standard deviation, they were represented as one input. Groups of cows were organized differently across the 20 farms, but could be broadly categorized as follows: transition cows (1 to $40 \mathrm{DIM}$ ), production groups (high, medium, and low), a single production group for the entire herd, first-lactation group, second and older lactation groups, nonlactating cows $>3$ wk from calving, and nonlactating cows $<3 \mathrm{wk}$ from calving. Input distributions ranged from a mean BCS of 2.5 to 4.0 , with a range of standard deviations of 0.12 to 0.68 . Ten thousand observations of BCS were generated for each input set. From each group of 10,000 observations, groups of $25,50,100$, and 150 cows were formed. Mean BCS were collected on samples (3.3 to $80 \%)$ of cows from each of these groups. The proportion of time the mean sample score was outside the $95 \%$ confidence range of the known mean, the BCS was determined for each sample proportion.

\section{Statistical Methods}

Mean BCS data and standard deviations for each observer were assessed by herd and method. Data for farm 1 was analyzed separately for the BCS determined by the live visit and by photos for each observer. The MIXED procedure (SAS Inst. Inc., Cary NC) was used to examine BCS, with fixed effects of observer, cow color, method (live vs. photo), and the interaction of observer $\times$ method. Cow was the repeated subject. Significance was determined as $P<0.05$. In addition, the mean BCS for the live and photo methods were compared within each observer for significance.

For herds 2 through 3, BCS was assessed from photos by observers 2 to 4 and assessed live by observer 1. The MIXED procedure was used to assess the effect of observer and color on BCS. The repeated effect was cow nested within farm.

The distribution of BCS for both groups by observers was analyzed using $\chi^{2}$ tests. Cows were grouped into general management categories of obese (BCS > 4.0), fat (BCS 3.75 and 4.0), acceptable (BCS 2.75 to 3.5, inclusive), thin (BCS 2.0 to 2.5 inclusive), and emaciated (BCS $<2.0$ ), based on modal BCS. A $\chi^{2}$ distribution was used to test the association of observer with distribution of BCS and general management categories within each method. Pearson correlation coefficients for BCS by method within observer (live vs. photo, farm 1 data) and across observers (farm 2 and 3 data) were calculated.

Table 3. Distribution of score categories by observer for body condition score (BCS) assessment made from cows at a farm visit and by assessment of photographs of cows.

\begin{tabular}{|c|c|c|c|c|c|}
\hline \multirow[b]{2}{*}{ Method } & \multirow[b]{2}{*}{ Category } & \multicolumn{4}{|c|}{ Observer } \\
\hline & & 1 & 2 & 3 & 4 \\
\hline \multirow[t]{4}{*}{ Live $^{1}$} & Obese $(\mathrm{BCS}>4.00)$ & 0 & 5 & 5 & 4 \\
\hline & Fat (BCS 3.75, 4.00) & 15 & 14 & 10 & 9 \\
\hline & OK (BCS 2.75-3.50) & 35 & 35 & 36 & 32 \\
\hline & Thin $(\mathrm{BCS} \leq 2.50)$ & 7 & 3 & 6 & 12 \\
\hline \multirow[t]{4}{*}{ Photo $^{2}$} & Obese $(\mathrm{BCS}>4.00)$ & 3 & 3 & 7 & 3 \\
\hline & Fat (BCS 3.75, 4.00) & 14 & 10 & 14 & 11 \\
\hline & OK (BCS 2.75-3.50) & 34 & 41 & 30 & 30 \\
\hline & Thin $(\mathrm{BCS} \leq 2.50)$ & 6 & 3 & 6 & 13 \\
\hline \multicolumn{6}{|c|}{ Observer, distribution of live vs. photo } \\
\hline$\chi^{2}$ & & 3.12 & 1.64 & 1.55 & 0.45 \\
\hline$P$ & & $<0.37$ & $<0.65$ & $<0.67$ & $<0.93$ \\
\hline
\end{tabular}



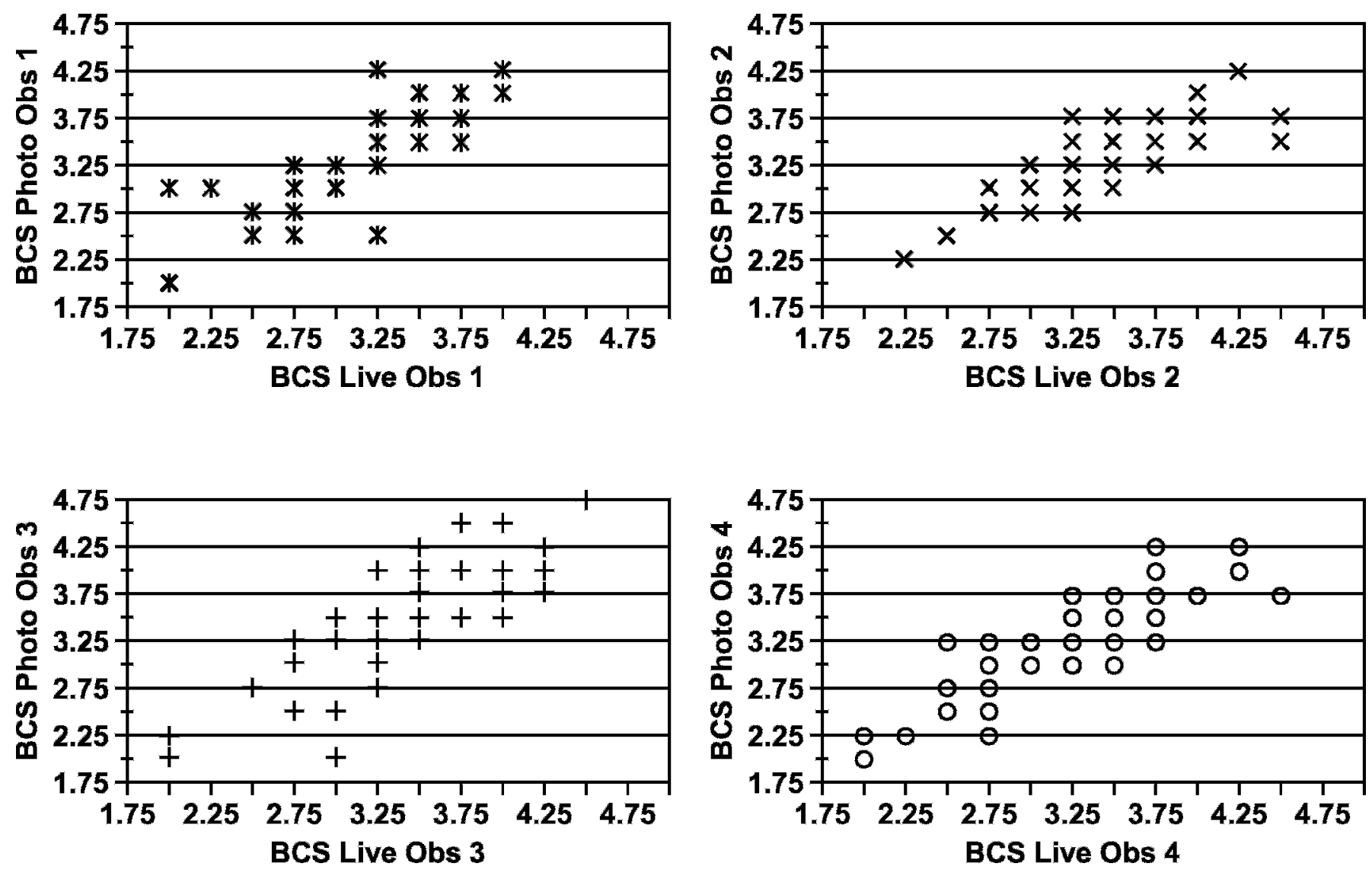

Figure 2. Body condition score assigned at a farm visit and later from a photograph for 4 observers ( $\mathrm{n}=57$; farm 1 ; SEM in parentheses). Observer $1=*$ Obs 1 ; BCS photo $=0.477(0.283)+0.824(0.073)$ BCS live; $\mathrm{R}^{2}=0.699$. Observer $2=\times$ Obs $2 ; \mathrm{BCS}$ photo $=0.281(0.284)+$ $0.945(0.088)$ BCS live; $\mathrm{R}^{2}=0.675$. Observer $3=+$ Obs 3 ; BCS photo $=0.679(0.333)+0.768(0.072)$ BCS live; $\mathrm{R}^{2}=0.677$. Observer $4=0$ Obs 4; BCS photo $=0.214(0.280)+0.928(0.062)$ BCS live; $\mathrm{R}^{2}=0.800$.

\section{RESULTS AND DISCUSSION}

It was soon apparent that BCS could not be distinguished from digital photos taken from lateral or anterior views of cows. Images made perpendicular to the longitudinal axis of a cow "flattened" prominences, so it was difficult to tell how much tissue covered bony projections. Anterior photos were taken from feed alleys looking down on cows in headlocks. Images taken from this perspective also tended to flatten body projections. Observers assessed that assigning a BCS from lateral and anterior imaging was not practically possible; therefore, these views were dropped from analyses.

Images from the rear of the cow enabled assignment of a BCS, and observers were comfortable assigning a BCS from these views. Images taken perpendicular and approximately 0 to $20^{\circ}$ relative to the horizontal plane of the tail head afforded good imaging for BCS assignment. Observers felt confident assigning a BCS to cows from a photograph taken at this view (Figure
1). As the angle relative to the tail head increased, observers found it more difficult to assign a BCS from a photograph. They reported problems similar to that of the lateral images, in which bony prominences were flattened, which made it difficult to detect the degree of fat covering. Therefore, only photographs taken perpendicular and approximately 0 to $20^{\circ}$ relative to the horizontal plane of the tail head were used in the final analyses.

Comparisons of BCS at farm 1 for the 4 observers are presented in Table 1. A total of 57 cows, ranging in modal BCS from 2.0 to 4.5 , were scored by each observer on the farm and from a digital image. Mean live BCS differed $(P<0.05)$ among the 4 observers, but these differences were small. The largest difference in mean live BCS, 0.29 units, was between observer 4, who had the lowest mean live BCS (3.13), and observer 2, who had the highest mean live BCS (3.42; Table 1). Observers 3 and 1 were intermediate in mean live BCS (3.33 and 3.25, respectively; Table 1). Across all 
Table 4. Mean BCS for 187 cows assessed at 2 farms by 1 observer (observer 1 ) and by 3 observers (observers $2,3,4)$ using digital images ${ }^{1}$

\begin{tabular}{|c|c|c|c|c|}
\hline \multirow[b]{2}{*}{ Parameter } & \multicolumn{4}{|c|}{ Observer } \\
\hline & 1 & 2 & 3 & 4 \\
\hline Mean $\mathrm{BCS}^{2}$ & $3.35^{\mathrm{a}}$ & $3.33^{\mathrm{ac}}$ & $3.60^{\mathrm{b}}$ & $3.26^{\mathrm{c}}$ \\
\hline SD & 0.55 & 0.49 & 0.54 & 0.62 \\
\hline Range & $2.00-5.00$ & $1.00-4.50$ & $1.00-4.75$ & $1.00-4.50$ \\
\hline \multicolumn{5}{|c|}{ Distribution } \\
\hline \multicolumn{5}{|c|}{ Thin and emaciated $(\leq 2.50)$} \\
\hline 1.00 & 0 & 1 & 1 & 1 \\
\hline 1.25 & 0 & 0 & 0 & 0 \\
\hline 1.50 & 0 & 0 & 0 & 0 \\
\hline 1.75 & 0 & 0 & 0 & 0 \\
\hline 2.00 & 10 & 1 & 2 & 7 \\
\hline 2.25 & 0 & 3 & 0 & 6 \\
\hline 2.50 & 9 & 7 & 5 & 17 \\
\hline Subtotal & 19 & 12 & 8 & 31 \\
\hline \multicolumn{5}{|c|}{ OK $(2.75-3.50)$} \\
\hline 2.75 & 6 & 17 & 7 & 19 \\
\hline 3.00 & 33 & 30 & 16 & 30 \\
\hline 3.25 & 28 & 38 & 21 & 17 \\
\hline 3.50 & 46 & 41 & 40 & 38 \\
\hline Subtotal & 113 & 126 & 84 & 104 \\
\hline \multicolumn{5}{|c|}{ Fat (3.75 and 4.00$)$} \\
\hline 3.75 & 31 & 26 & 37 & 21 \\
\hline 4.00 & 14 & 18 & 29 & 19 \\
\hline Subtotal & 45 & 44 & 66 & 40 \\
\hline \multicolumn{5}{|c|}{ Obese $(>4.00)$} \\
\hline 4.25 & 4 & 3 & 18 & 5 \\
\hline 4.50 & 4 & 2 & 10 & 7 \\
\hline 4.75 & 1 & 0 & 1 & 0 \\
\hline 5.00 & 1 & 0 & 0 & 0 \\
\hline Subtotal & 10 & 5 & 29 & 12 \\
\hline Total & 187 & 187 & 187 & 187 \\
\hline
\end{tabular}

${ }^{\mathrm{a}-\mathrm{c}}$ Values within a row with different superscripts differ $(P<0.05)$.

${ }^{1}$ Digital images taken from the rear of the cow, parallel to the spinal axis, and at a 0 to $20^{\circ}$ angle relative to the tail head.

${ }^{2} \mathrm{SE}=0.04$.

observers, the mean live BCS for the cows was $3.28 \pm$ $0.06( \pm \mathrm{SE})$.

Within observers, the mean photo BCS did not differ from the mean live BCS (Table 1). The mean photo BCS differed $(P<0.05)$ among observers, and the range in highest to lowest scores (0.30) was similar to the range in mean live BCS (Table 1). The highest photo mean BCS was for observer 3 (3.44), whereas observer 2 had the highest mean live BCS (3.42; Table 1). The mean BCS for observers 1, 2, and 3 changed by an absolute value of approximately 0.11 units between methods, whereas the mean BCS for observer 4 changed by only 0.01 units (Table 1 ). Overall, the mean photo BCS was $3.32 \pm 0.06( \pm \mathrm{SE})$ and did not differ from the mean live BCS. The correlation coefficient of BCS between the live and photo methods across all observers was 0.84 (Table 1). The correlation coefficient between the live and photo methods within observer ranged from 0.82 to 0.90 (Table 1 ).

The distribution of differences in BCS (BCS live minus BCS photo) by cow for each observer is presented in Table 2. The differences in BCS were within \pm 0.25 units for the live and photo methods (range $=71.9$ to $86 \%$ for the 4 observers; Table 2 ), which is typical when observers assign repeated BCS to the same cow several different times (Ferguson et al., 1994). A similar score was given to the same cow at frequencies of $43.9,47.4$, 22.8 , and $40.4 \%$ of the time for observers 1 through 4 ,

Table 5. Correlation between BCS assessed live (observer 1) vs. with a digital photograph taken from the posterior of the cow (observers 2, 3, and 4) for 187 Holstein cows from 2 dairy farms ${ }^{1}$

\begin{tabular}{lllll}
\hline Observer & 1 & 2 & 3 & 4 \\
\hline 1 & & $0.77^{* * *}$ & $0.76^{* * * *}$ & $0.79^{* * *}$ \\
2 & & $0.78^{* * *}$ & $0.85^{* * *}$ \\
3 & & & & $0.87^{* * *}$ \\
\hline
\end{tabular}

${ }^{1}$ Live $=$ BCS assigned by visual and tactile observation of cows restrained in head locks, standing in free stalls, or in open lots; photo $=$ BCS assigned by examining a digital photo made from behind the cow at a 0 to $20^{\circ}$ angle to the tail head, parallel to the spinal axis.

$$
* * * P<0.001 \text {. }
$$




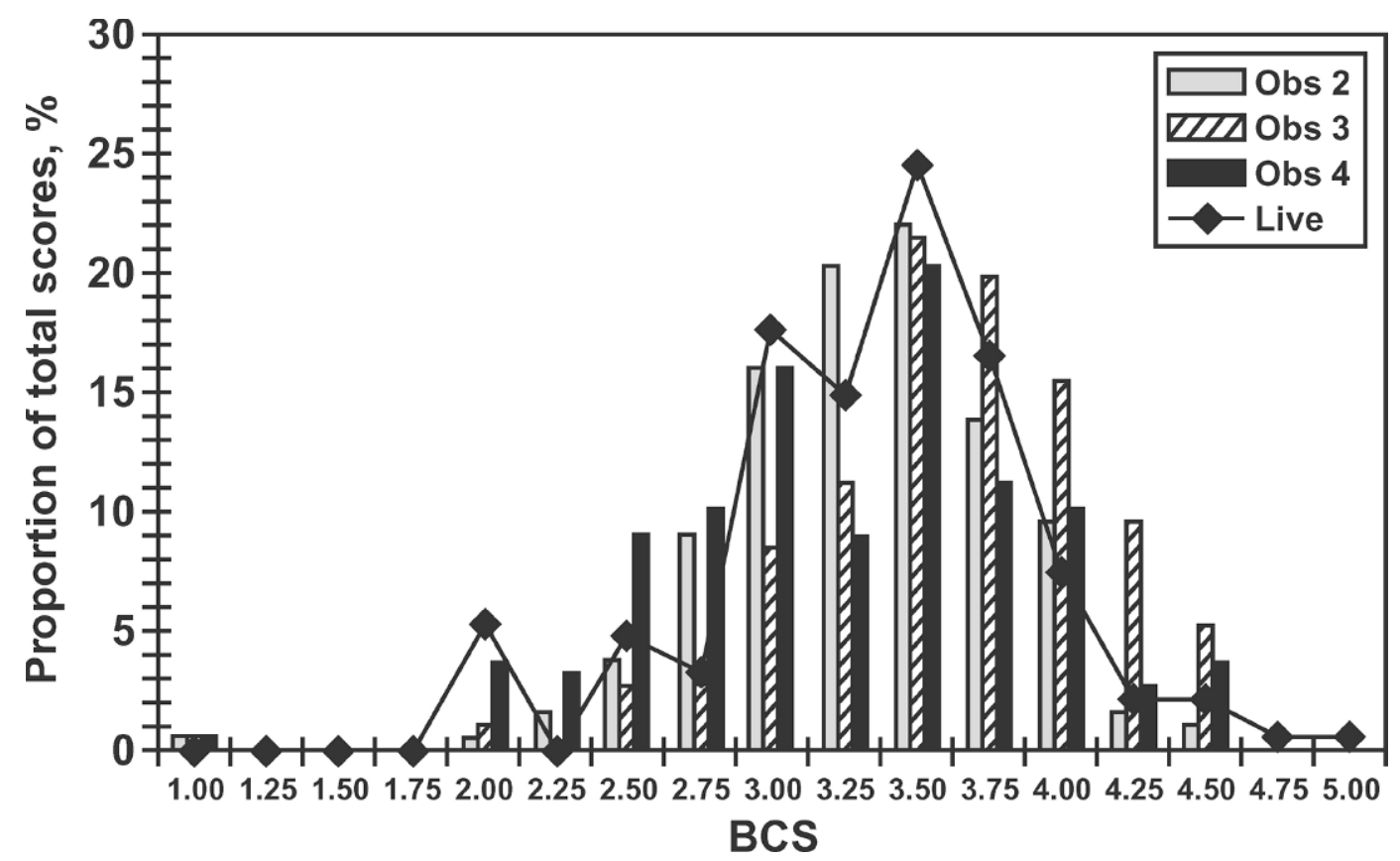

Figure 3. Frequency of BCS observations assessed live (observer 1, "live") and from photographs (observers 2,3 , and 4 ) at 2 farms (n = 187: $\mathrm{n}=56$ and $\mathrm{n}=131$ at farms 2 and 3 , respectively).

respectively (Table 2). Observers 1 and 2 assigned a lower score to 24 and 31 of the 57 cows, respectively, when looking at a photo, whereas observer 2 assigned a higher score to 21 of 57 cows when looking at a photo. Observer 4 was uniform in reassigning scores, with 18 scores lower and 16 scores higher from the photo than the live BCS. The color or location of the cow (restrained in a lockup, standing in a free stall, standing in bedded pack) did not influence the change in BCS from the live to the photo method.

Figure 2 presents the distribution of BCS from photos plotted against the live BCS for the 4 observers. The slope of the change in BCS $( \pm \mathrm{SEM})$ was $0.82(0.07)$, 0.95 (0.09), 0.77 (0.07), and 0.93 (0.06) for observers 1 , 2,3 , and 4 , respectively. No obvious bias was detected when assigning BCS from photographs or from the farm visit for cows that were thin, average, or fat. A closer inspection of the BCS categories is presented in Table 3.

Often a group of cows is assessed for the proportion considered to be "obese" (BCS > 4.0), "fat" $(\mathrm{BCS}=3.75$ or 4.0), "OK" (BCS $=2.75$ to 3.50 , inclusive), "thin" ( $\mathrm{BCS}=2.00$ to 2.50 , inclusive), or "emaciated" (BCS < 2.00). Frequencies for these categories for each observer for the live and photo methods are shown in Table 3. No difference was detected across or within observers for the proportion of cows classified in these categories by method (Table 3). Although the mean BCS differed across observers, classification of cows as "too thin" or "too fat" did not differ across observers. Conclusions of the mean BCS and distribution in BCS categories were similar across observers and for each method (live vs. photo) for this farm.

Because all observers had visited farm 1, the earlier observation of cows may have biased the BCS assigned from a photograph. To examine whether the BCS could be ascertained from a photograph alone, two farms (131 and 56 cows, respectively) were visited by observer 1, who assigned a BCS to a cow and photographed the cow. Observers 2, 3, and 4 assigned a BCS to a cow based only on the photo. Table 4 presents the mean BCS for cows assigned a BCS from a live visit vs. observers assessing the BCS from a photograph. The mean BCS assigned by observers 1,2 , and 4 did not differ. The mean BCS for observer 3 was greater than those of the other observers (Table 3), which was a trend for this observer with observations made from photographs for farm 1 (Table 1). Observer 4 assigned the smallest mean BCS to cows (Table 4) as he had for cows on farm 1 (Table 1). The standard deviations of BCS were similar for all observers and were approximately 0.5 BCS units (Table 4).

The distribution of BCS for each observer for farms 2 and 3 also is presented in Table 4 . The distribution of BCS was different for all 4 observers $\left(\chi^{2}=57.87\right.$; $\mathrm{df}=9$ ). Distributions differed because of the tendency for observer 3 to score higher and observer 4 to score lower than observers 1 and 2. Observer 1 and 2 did not 


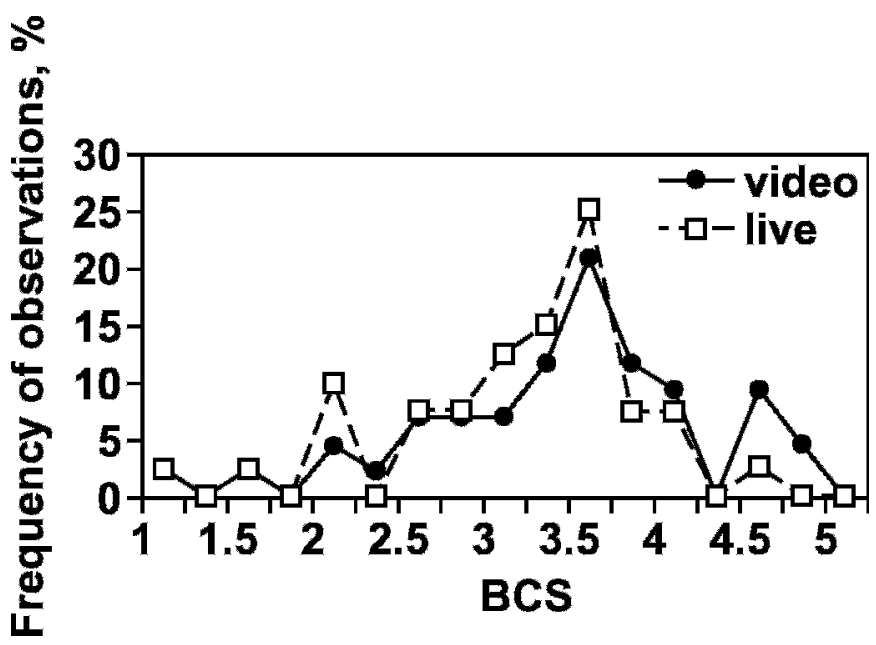

Figure 4. Proportions of cows assigned a BCS live by 1 individual on a farm visit and $2 \mathrm{wk}$ later by using a video made from the rear of the cows at a 0 to $20^{\circ}$ angle relative to the tail head while cows were restrained in lockups at a feed bunk.

differ in the distribution of scores. The most extreme difference in BCS distribution was for observer 3, who scored cows higher from the photographs for farms 2 and 3. All observers ranked the BCS for farms 2 and 3 as having an excessive proportion of fat and obese cows, $29.4,26.2,50.8$, and $27.8 \%$ of all observations for observers $1,2,3$, and 4 , respectively (Table 4 ). The proportions of cows considered thin were 10.2, 6.4, 4.3, and $16.6 \%$ for observers $1,2,3$, and 4 respectively.

Correlation coefficients between observers for farms 2 and 3 are shown in Table 5. Correlation coefficients

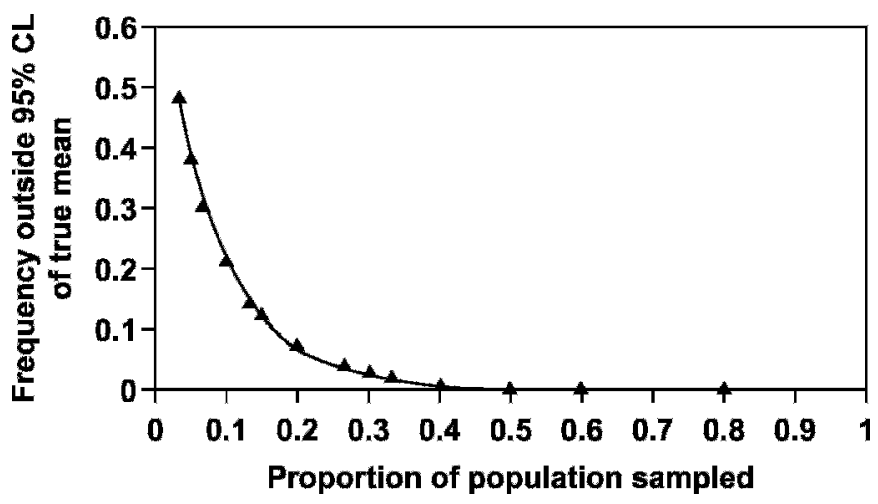

Figure 5. Proportion of times an estimate of the mean BCS would lie outside the $95 \%$ confidence limit (CL) of the true mean of a group of cows as a function of the proportion of the group assigned a BCS. Proportions are based on inputs from 17 groups of cows with observed mean BCS ranging from 2.66 to 4.0 and standard deviations ranging from 0.12 to 0.68 . Ten thousand observations were generated for each group. Groups of 25, 50,100, and 150 cows were created for sample sizes of 3 to $80 \%$ of the group to estimate the mean BCS. Frequency $=$ $0.69 \times \exp (-11.56 \times$ proportion sampled $)$. among observers 2,3 , and 4 (photo only) with observer 1 (live only) ranged from 0.76 to 0.79 (Table $5 ; P<$ 0.001 ). Those among observers 2,3 , and 4 ranged from 0.78 to 0.87 (photo only; Table 5; $P<0.001$ ). Frequencies of BCS for observer 1 (live) and for observers 2 , 3 , and 4 (photo) for farms 2 and 3 combined are presented in Figure 3. The distribution of BCS for each method and observer is similar.

The distribution of BCS assigned by observer 1 from a farm visit was similar to that later assessed by observer 1 from a video of the cows produced by a different individual (Figure 4). The video allowed interactive viewing of animals by the observer, and rapid assessment of BCS could be made for each cow. Individual cow identification could not be made from the video, which focused on imaging cows from the posterior.

Figure 5 presents the proportion of observations in which the estimate of the mean BCS for the group of cows would fall outside the $95 \%$ confidence limit of a known mean BCS when sampling 3 to $80 \%$ of the cows in a group. A sample size of 22.7 or $36.6 \%$ of a group would fall within the $95 \%$ confidence limit of the true mean 95 and $99 \%$ of the time, respectively (Figure 5). A sample size of $30 \%$ of a group would fall outside the $95 \%$ confidence limit of the true mean of the group $<2 \%$ of the time. Therefore, a sample size of $30 \%$ seems sufficient to estimate the mean BCS of a group of cows.

\section{CONCLUSIONS}

Assessment of BCS in dairy cattle is possible from digital photographs or a video taken from the rear of a cow at a 0 to $20^{\circ}$ angle relative to the tail head. A sample size of $30 \%$ is adequate to estimate the mean BCS of a group of cows. Body condition can be assessed by observers from images taken on the farm without visiting the farm.

\section{ACKNOWLEDGMENTS}

The authors thank Consorzio Ricerca Filiera Lattiero Casearia for support for the project and the farm owners who cooperated for imaging and body scoring of their cows.

\section{REFERENCES}

Domecq, J. J., A. L. Skidmore, J. W. Lloyd, and J. B. Kaneene. 1997a. Relationship between body condition scores and conception at first artificial insemination in a large dairy herd of high yielding Holstein cows. J. Dairy Sci. 80:113-120.

Domecq, J. J., A. L. Skidmore, J. W. Lloyd, and J. B. Kaneene. 1997b. Relationship between body condition scores and milk yield in a large dairy herd of high yielding Holstein cows. J. Dairy Sci. 80:101-112.

Edmonson, A. J., I. J. Lean, L. D. Weaver, T. Farver, and G. Webster. 1989. A body condition scoring chart for Holstein dairy cows. J. Dairy Sci. 72:68-78. 
Ferguson, J. D., D. T. Galligan, and N. Thomsen. 1994. Principal descriptors of body condition in Holstein dairy cattle. J. Dairy Sci. 77:2695-2703.

Gearhart, M. A., C. R. Curtis, H. N. Erb, R. D. Smith, C. J. Sniffen, L. E. Chase, and M. D. Copper. 1990. Relationship of changes in condition score to cow health in Holsteins. J. Dairy Sci. 73:3132-3140.

Komaragiri, M. V. S., and R. A. Erdman. 1997. Factors affecting body tissue mobilization in early lactation dairy cows. 1. Effect of dietary protein on mobilization of body fat and protein. J. Dairy Sci. 80:929-937.

Otto, K. L., J. D. Ferguson, D. G. Fox, and C. J. Sniffen. 1991. Relationship between body condition score and composition of the ninth to eleventh rib tissue in Holstein dairy cows. J. Dairy Sci. 74:852-859.

Overton, M. W., W. M. Sischo, G. D. Temple, and D. A. More. 2002. Using time-lapse video photography to assess dairy cattle lying behavior in a free-stall barn. J. Dairy Sci. 84:2407-2413.

Ruegg, P. L., and R. L. Milton. 1995. Body condition scores of Holstein cows on Prince Edward Island, Canada: Relationships with yield, reproductive performance, and disease. J. Dairy Sci. 78:552-564.

Wildman, E. E., G. M. Jones, P. E. Wagner, and R. L. Bowman. 1982. A dairy cow body condition scoring system and its relationship to selected production characteristics. J. Dairy Sci. 65:495-501. 